those students who are likely to proceed to the highest work in pure mathematics. Schedule B comprehends the highest kind of work in all parts of pure and applied mathematics which may be expected from men of the age and experience of the best candidates.

The examination in part ii. comprises the subjects in Schedules A and B. Schedule A contains the ordinary subjects to be taken by all candidates, the $B$ subjects being taken only by men who are candidates for a mark of distinction. Six papers will be set on $\mathrm{A}$ and not more than six papers on $\mathrm{B}$. In each of the papers on $\mathrm{A}$ there will be set some simple questions specially indicated, partly on the syllabus of part i.; a candidate who answers these questions sufficiently well will be entitled to honours. The questions on the varjous subjects will be distributed among the papers at the discretion of the examiners. Some months before the examination the registrary must be furnished with names of students who intend to present themselves as candidates for distinction in subjects B, specifying their special subjects or branches of subjects; and still some time before the examination students will specify the range of subjects $B$ in which they desire to be examined. It is again laid down, as in part i., that there will be tests of knowledge of phenomena in the physical questions, and simple numerical or other illustrations will be given. Also the questions on even the subjects of Schedule B will consist in part of questions of an elementary or simple character. Part ii. cannot be taken earlier than in the eighth term. The list of successful candidates for honours will be in three classes, wranglers, senior optimes, and junior optimes, the names in each being in alphabetical order. The class in which a man is placed depends usually on his answers in Schedule A, but in case of doubt his answers to B may be consulted. A distinctive mark is attached to the name of a man who has done fairly well in Schedule B, and a different mark if he deserves special credit for his answers to $B$.

Now there is no doubt that much depends upon the spirit in which an examiner acts; he may greatly help or hurt the desires of the reformers, but surely this reform is a great step in the right direction. The old order of merit did incalculable harm. Candidates spent far too much time in the details of the general mathematical course, and as straightforward questions would have been answered equally well by all the good men, to differentiate them it was necessary to set questions which were complex and indeed tricky. Again, a just order of merit can be arranged only if all students are examined in the same subjects, and to compel all students to study the same subjects in the one way that leads to success in such an examination is uneducational. Not only has the course of study been mischievous for physicists and engineers, who ought to be allowed to advance quickly to those parts of higher mathematics which are necessary for them, but it is utterly uninteresting and hateful to the general student, for whose culture it might be made valuable. The greatest sufferer hitherto, however, has been the real mathematician, who is drilled so long on elementary work that even after he becomes a wrangler he is only ready to begin that higher work which he might have studied years before. In nineteen cases out of twenty he has become stale, so that even when he becomes a teacher of mathematics he is no longer a student. it would be useless for us to express an opinion as to the effect of the examination upon those Cambridge pure mathematicians from whom an advancement of knowledge might be expected; a senior wrangler of European reputation has given a curious opinion in NATURE, February 12, 1903, p. 339.
This reform will be far-reaching; it will extend to all places in Great Britain where a Cambridge man teaches, and to all examinations in which the Cambridge examiner has been in the habit of setting riddles and conundrums as questions. A large general committee has been formed of men who think that the regulations should be approved. It is representative of Cambridge at its best, not merely in men who teach, but in men who are doing original work in pure mathematics and mathematical physics and engineering, as well as in history and literature, scholars and workers of all kinds. It would be invidious to compare with these the names of the men who have organised the opposition. A scrutiny of the October votes shows that the members of Senate who are resident in Cambridge are in favour of reform by majorities considerably more than in the case of the general members. The opponents of reform now call upon all country members to come to Cambridge and record their votes. Should they persist in their intention, it is just possible that they may succeed in reversing the recent decision of the Senate; but if they do they are establishing a precedent which cannot conduce to the smooth and consistent working of the University.

There is another matter for these gentlemen to consider. Should they succeed, it is certain that the reformers will ask for and obtain a Parliamentary Commission. Is it likely that such a commission will inquire only into the question of mathematics? There is the Greek question, and there are others which the opponents of reform surely do not wish to have examined. Some of us wish that they would persevere and defeat the reformers, so that our greatest university might through a commission get those other reforms which it is hopeless to expect from the Senate.

JOHN PERry.

\section{THE INTERNATIONAL SEISMOLOGICAL ASSOCIATION.}

T HE first meeting, since its definite organisation, of the committee of the International Seismological Association was held at Rome on October I6, 1906, and was attended by representatives of each of the States belonging to the association. The United States having quite recently joined, the only important outstanding countries at present are Great Britain and France. The answer of France has not yet been received, while Great Britain has signified its intention to join under certain conditions, among which the simultaneous adhesion of France is the only one which at present prevents our country from being a member of the association. Nevertheless, both countries sent representatives to the meeting, M. Bigourdan acting for France and Prof. Schuster for Great Britain.

The time of the meeting was taken up in great part by questions of organisation, as, for instance, the drawing up of regulations concerning the procedure of the committee itself. Prof. Palazzo, of Rome, occupied the chair, and was re-elected president until the general meeting of the association, which is to take place in September. Reports were presented from the various States showing the organisation of the seismic service in the different countries, and these reports gave evidence of the great interest now generally taken in the seismic tremors of the earth.

The more important scientific questions submitted to the conference were deferred for decision to the general meeting in the present year, but it was decided to supply the Arctic station of Disko with an instrument for measuring the vertical component of disturbances, and to open a competition for the 
construction of a seismograph which shall be suitable for the measurements of tremors having their source near the place of observation. Advertisements giving details of this competition have appeared in various papers in this country (see Nature, January 3, p. xci).

It may be remembered that an organisation for studying the propagation of earthquakes was discussed at the last meeting of the International Association of Academies held in London in $190_{5}$, and that a committee was then appointed to formulate the views of the united academies, the originally proposed scheme for the seismic organisation not having met with general approval. This committee met, and its recommendations were subsequently approved by the council of the International Association of Academies. The International Seismological Association has accepted the suggested modifications, the general tenor of which was to safeguard the internal organisation of the earthquake observations in different countries, confining the international work to those physical questions of earthquake propagation which can obviously only be dealt with on an international basis. It is to be hoped that the spirit of these modifications will be adhered to, and that no attempt will be made to encroach on the functions which more definitely concern each country separately. We are glad to note, therefore, from the proceedings of the recent conference that both the questions of a more particular study of the districts surrounding Vesuvius, which primarily concerns Italy, and the foundation of a station in Iceland, which primarily concerns Denmark, were postponed.

The social functions of the international meeting were well looked after at Rome, the members bein? most hospitably entertained, and also provided with tickets enabling them to travel at about half-fare over all State railways during the meeting, and for several days before and after.

\section{SCIENCE IN HIGHER EDUCATION.}

$\mathrm{I} T$ is satisfactory to notice the attention now being given to scientific methods in education, not only by teachers and others actively engaged in educational work, but also by prominent statesmen. During the past week several important educational conferences have been held, and a report of one specially organised by science teachers appears elsewhere in this issue. But the dominating note of other conferences concerned with the school curriculum in general and subjects belonging to the literary side of education in particular is that of scientific method. Whether in the study of ancient or modern languages, in the cultivation of mental attitudes or the development of the body, it is clear that authoritative opinion considers the best methods of teaching should be based upon principles which have long been advocated by men of science. The little leaven of science is leavening the whole lump of educational effort, and the result is gratifying to contemplate.

Provided that scientific methods are adopted, that is, methods which aim at making pupils work out their own intellectual salvation, it does not matter much what subjects are studied. What we have always wished to avoid, and what we are glad to see now meets with unanimous disapproval, is instruction which is not education, the drudgery of learning phrases or performing mental gymnastics in literature, mathematics, or science without attention to the more valuable faculties of critical thought and originality. From the condition of a passive absorber of teachers' notes and the pemmican of textbooks of former days, the pupil is gradually being recognised as an active agent who may be led to make his own observations and form his own conclusions, whatever the subject of study may be. It can scarcely be said at present that the old methods have disappeared from our schools and colleges-the requirements of the old universities and examining bodies prevent this end from being reached-but the feeling of practically all active thinkers and workers in the world of education is in favour of the adoption of principles with which we are completely in sympathy, and their influence is gradually giving the spirit of life to what have been the dead bones of school work.

Our statesmen, also, and in particular Mr. Haldane, Secretary of State for War and president of the British Science Guild, are taking opportunities to impress upon the nation the essential part which science and higher education must play in the polity of the modern State if progress is to be secured. We are glad, therefore, to extract from reports of speeches made last week by $\mathrm{Mr}$. Haldane and $\mathrm{Mr}$. Asquith some remarks expressing conviction of the value of factors which have long been recognised in these columns as essential to national welfare.

\section{Scientific Thought.}

An international economic congress, arranged by the council of the Royal Economic Society, was held on January 9 and to at the London School of Economics. Mr. Haldane, M.P., occupied the chair during the earlier portion of the morning session on the first day as president of the society, and delivered the introductory address. Mr. Haldane is reported by the Times to have said:- Whatever other differences there may be between the nations, there is a brotherhood-a brotherhood the reality of which is asserting itself more as year succeeds year-the brotherhood of science. We are to-day recognising that in science, as well as in other things, international cooperation is essential, and perhaps in no department is that more marked than in the department which deals with the science of the State. It is not only in economics that this kind of wider outlook is beginning to come to people. In science of every kind we have witnessed the tendency of the nations to specialise. Perhaps it is more easy to preserve a common basis in those sciences which do not touch human nature; but there is one thing that is true of all sciences, and that is that their methods are necessarily abstract. Do not let us be carried away with the notion that because a method is abstract, therefore it is not an indispensable method for getting at the truth. It is obvious that the chances of reaching the truth are greater in certain cases, the greater the abstractness of the method.

I have at this moment two books in my mind, books which, in a sense, are to-day out of date, but which, in another sense, will never be cut of date, because they are the most perfect illustrations of true scientific methodthe method which does not allow itself to shut out of view facts by the narrowness of its conceptions. One is Darwin's "Origin of Species," the other is Adam Smith's "Wealth of Nations," a book written by a man who had profoundly freed his mind from every kind of narrowness.

After dealing with the value to statesmen of the study of economics, Mr. Haldane spoke of the internationalism of science. He remarked:-It seems to me that this tendency to the internationalism of science, which is again, after 300 or 400 years, beginning to set in, which does not depend on our speaking a common language, but does depend on our becoming more and more specialists working out different departments of great and complicated questions-it seems to me that this new tendency is one which should fill us with hopefulness for the future. It has been said, and said with truth, that this is not an age of great men. We do not seem to be producing a Newton or a Gauss, a Helmholtz or a Laplace with the frequency with which former generations produced these outstanding figures; and yet, on the other hand, who will doubt that the general level of science is far higher to-day than it was a generation ago, and still highei than it was a generation before that? People have rcalised that it is

NO. I942, VOL. 7.5$]$ 